\title{
Agrobiodiversidade e a etnobotânica na comunidade São Benedito, Poconé, Mato Grosso, Brasil
}

\author{
Agricultural biodiversity and ethnobotany at São Benedito community Poconé, \\ Mato Grosso, Brazil
}
La biodiversité agricole et ethnobotanique à la communauté São Benedito, Poconé, Mato Grosso, Brésil
La biodiversidad agrícola y etnobotánica en São Benedito comunidade Poconé, Mato Grosso, Brasil

\author{
Gisele Soares Dias Duarte* \\ (gsdduarte@hotmail.com) \\ Maria Corette Pasa* \\ (pasamc@brturbo.com.br)
}

Recebido em 09/12/2014; revisado e aprovado em 08/04/2015; aceito em 11/10/2015

DOI: http:/ / dx.doi.org/10.20435/1984042X2016208

\begin{abstract}
Resumo: A coleta dos dados foi realizada através de entrevistas participativas, seguindo um questionário semiestruturado e estruturado com questões abertas, além de visitas no local. As roças apresentam diversas espécies na mesma área, sendo a mandioca o principal cultivo. Os quintais possuem vasta diversidade vegetal, destacando-se as espécies alimentícias e medicinais. Assim, tanto os quintais quanto as roças auxiliam na subsistência e na renda das famílias quilombolas dessa comunidade.

Palavras-chave: manejo; quintais; roça.

Abstract: Data collection was conducted through participatory interviews following a semi-structured questionnaire and structured with open questions, as well as site visits. The gardens feature several species in the same area, with the main cassava cultivation. The yards have vast plant diversity, highlighting the nutritional and medicinal species. Thus, both yards as the fields assist in sustaining the income of the Quilombo families of this community.

Key words: management; backyards; farm.

Résumé: La collecte des données a été réalisée au moyen d'entrevues participatives Après le questionnaire semi-structuré et structuré avec des questions ouvertes, ainsi que des visites de sites. Les jardins qui comptent plusieurs espèces dans la même zone, avec la principale culture du manioc. Les chantiers ont une grande diversité végétale, en soulignant les espèces nutritionnelles et médicinales. Ainsi, les deux chantiers dans les champs aider à soutenir les revenus des familles Quilombo de cette communauté.

Mots-clés: gestion; backyards; ferme.

Resumen: La recolección de datos se realizó a través de entrevistas participativas Tras el cuestionario semi-estructurado y estructurado con preguntas abiertas, así como visitas a los sitios. Los jardines cuentan con varias especies de la misma zona, con el cultivo principal de la yuca. Los patios tienen gran diversidad de plantas, destacando las especies alimenticias y medicinales. Así, tanto yardas a los campos de ayudar en el sostenimiento de los ingresos de las familias Quilombo de esta comunidad.

Palabras clave: gestión; patios traseros; granja.
\end{abstract}

\section{INTRODUÇÃO}

A etnobotânica desponta como um campo interdisciplinar que compreende o estudo e a interpretação do conhecimento, significação cultural, manejo e usos tradicionais dos elementos da flora (CABALLERO, 1979). Além disso, segundo Pasa (2011), é um método utilizado para resgatar o conhecimento e saber botânico existente nas comunidades tradicionais com particularidade para o uso da flora.
No seu início, a Etnobotânica tinha um caráter mais restrito, estudando as interrelações entre os vegetais com as sociedades ditas "primitivas". Com o passar do tempo, essa limitação foi sendo superada e sua investigação expandiu-se, fazendo parte agora do seu campo de estudo, não somente as sociedades indígenas, mas também as sociedades industriais e suas relações estabelecidas com a flora (ALBUQUERQUE, 2005).

Além de o conhecimento etnobotânico contribuir para o conhecimento científico

* Universidade Federal de Mato Grosso (UFMT), Cuiabá, Mato Grosso, Brasil. 
das espécies vegetais, seu estudo deve ter foco, também, na reversão do conhecimento fornecido pelos informantes para sua própria comunidade. Dessa forma, a etnobotânica não serve apenas como ferramenta para resgatar o conhecimento tradicional, mas também é importante no resgate dos próprios valores das culturas com que se entra em contato (PRANCE, 1987; DELWING et al., 2007).

Os sistemas tradicionais de manejo altamente adaptados a ecossistemas específicos estão cada vez mais caindo em desuso, seja pela introdução da economia de mercado, pelo processo de aculturação, seja por substituição por outros sistemas chamados "modernos" impostos de fora das comunidades (DIEGUES, 2001), porém cada vez mais é necessário resgatar os sistemas de manejo adotados por essas populações, pois já se sabe que essas técnicas contribuem significativamente para a manutenção da agrobiodiversidade.

O manejo adaptado a ecossistemas específicos está sendo substituído pela introdução de elementos externos utilizados nos sistemas convencionais de produção vegetal, como produtos sintéticos. Diante da marcha acelerada da urbanização, exploração dos ambientes naturais e das possíveis mudanças culturais, é preciso resgatar o conhecimento que as populações tradicionais detêm sobre a agrobiodiversidade, bem como as formas de cultivo e uso desses recursos naturais (CARNEIRO, 2009).

Segundo a FAO (1999), a agrobiodiversidade consiste na diversificação de plantas, animais e microrganismos utilizados direta ou indiretamente para alimentação e agricultura, incluindo a diversidade dos recursos genéticos e espécies utilizadas para fins medicinais, fibra e combustível. Assim, a agrobiodiversidade não inclui apenas espécies alimentícias, mas também espécies que são utilizadas para fins terapêuticos e matéria-prima. A agrobiodiversidade é gerida por agricultores, sem os quais muitos componentes não sobreviveriam à interferência humana. Nesse contexto, o conhecimento local e a cultura são considerados partes integrantes da gestão da biodiversidade agrícola, pois molda e conserva essa dinâmica relação entre sociedades humanas e as plantas (CONWAY, 1987; FAO, 1999; MARZALL, 2007).

A agrobiodiversidade constitui-se num sistema agrícola, no qual se procura associar conservação e manejo com desenvolvimento sustentável (SANTOS, 1996). Essas ações podem ser adaptadas às comunidades tradicionais, a fim de ajudá-las no desenvolvimento local, na tentativa de apresentar respostas às comunidades tradicionais. Nesse sentido, o conhecimento local e a cultura podem ser considerados partes integrantes do etnoagrícola e da diversidade, pois é a atividade humana da agricultura que molda e conserva as espécies. Os sistemas agroflorestais como quintais e roças são considerados sistemas altamente conservadores da diversidade agrícola e cultural em todas as faixas tropicais do mundo (MACHADO et al., 2008).

O objetivo do trabalho foi caracterizar a agrobiodiversidade local através de um levantamento etnobotânico das espécies vegetais (alimentícias e medicinais) encontradas em quintais e roças na comunidade São Benedito, Poconé, Mato Grosso, Brasil.

\section{MATERIAL E MÉTODOS}

\section{1 Área de estudo}

A pesquisa foi realizada na comunidade São Benedito, localizada no município de Poconé, situada na mesorregião do Alto Pantanal e microrregião Centro Sul de Mato Grosso, área denominada de Baixada Cuiabana. Na área predomina o clima tropical quente e subtropical quente e subúmido. A precipitação média anual é de $1.500 \mathrm{~mm}$, cuja intensidade máxima ocorre em Dezembro, Janeiro e Fevereiro. A temperatura média anual é de $24^{\circ} \mathrm{C}$, a máxima de $42^{\circ} \mathrm{C}$, e a mínima de $4^{\circ} \mathrm{C}$ (IBGE 2010).

O município de Poconé possui uma população de aproximadamente 32.092 habitantes, sendo que $27,43 \%$ vivem na zona rural (IBGE, 2010). A agricultura e pecuária são as principais atividades econômicas, destacando-se na produção da farinha de mandioca, muito apreciada pela população regional e nos grandes centros urbanos do país.

Atualmente, a comunidade São Benedito é constituída por aproximadamente 26 famílias. Historicamente, sua formação se deu na década de 50, quando a área que habita a comunidade era um sítio, cujo dono doou para pessoas que quisessem plantar e morar no local. Na década de 70, a comunidade São 
Benedito foi registrada como tal, e as famílias que nas redondezas moravam começaram a migrar para o local, em busca de um pedaço de terra para exercer a agricultura. A comunidade se localiza a $104 \mathrm{~km}$ da capital Cuiabá e a $50 \mathrm{~km}$ de Poconé, cidade mais próxima à comunidade.

\subsection{Coleta de dados com os informantes}

Os dados foram coletados no período de junho de 2014 a fevereiro de 2015, com periodicidade mensal e com duração de três dias cada visita. As entrevistas foram realizadas nas residências, quintais e roças junto aos moradores, com o objetivo de coletar dados etnobotânicos e identificar as espécies vegetais.

Os informantes foram selecionados de início ao acaso e, posteriormente, de acordo com a indicação dos entrevistados, o que resultou num total de 41 pessoas entrevistadas, em diferentes pontos que determinam a área de estudo.

Para a coleta dos dados, foram utilizados o Pré-teste e entrevistas, realizadas nas residências, quintais e roças junto aos moradores, com o objetivo de coletar dados etnobotânicos e identificar as espécies vegetais seguindo um questionário com questões abertas, além de visitas no local. Conforme a orientação da entrevista sobre a comunidade, muitos informantes partiram para a história oral, que é essencialmente uma história da vida, transmissão de fatos, testemunho (MEYHY, 1996). Também foi utilizado o registro fotográfico, GPS para obtenção das coordenadas de cada ponto, o gravador de voz para garantir maior integridade das entrevistas, conforme o consentimento dos dependentes, bem como o Consentimento Livre e Esclarecido para participar de forma espontânea da pesquisa.

\section{RESULTADOS E DISCUSSÃO}

Através do pré-teste, abordou-se: sexo, idade, estado de origem, grau de instrução, tempo que reside no local, religião e atividade que desempenha atualmente. Um total de 41 pessoas foi entrevistado representando a unidade amostral. Do total dos depoentes, $48,78 \%$ são do sexo feminino, e $51,21 \%$ são do sexo masculino. Todos os informantes trabalham em sua propriedade e na farinheira comunitária da comunidade. A idade dos informantes variou de 25 a 76 .

Quanto ao nível de escolaridade, 42\% possuem o ensino primário completo, o ensino fundamental incompleto, e estudantes somam $26,82 \%$, entre nível fundamental e superior. Com nível superior, foram 4,87\% (dois informantes), um do sexo feminino outro masculino, ambos cursando Pedagogia e nascidos na comunidade e, mesmo com nível superior, desempenham a função de agricultor nas suas roças, e 12,19\% não possuem escolaridade. Além disso, muitos jovens priorizam as tarefas domésticas, o trabalho na roça e nas cidades para complementar a renda familiar.

Quando os jovens partem para a cidade em busca de trabalho, também surge a oportunidade de completar os estudos, pois a comunidade oferece apenas o ensino fundamental, e o acesso à escola para o ensino médio é dificultada por falta de transporte na comunidade. Este resultado é visto também por Martins et al. (2012), que, trabalhando com a comunidade Boca do Moa no Acre, verificou que muitos jovens possuem condições de estudar, mas o problema passa a ser o acesso à sala de aula, principalmente pela distância do local, ainda um problema na Amazônia. A Tabela 1 apresenta os dados de local do nascimento e o tempo de moradia no local. Do universo de 41 entrevistados, 78,04\% são nascidos na comunidade São Benedito, e o restante, na região como Poconé, Cuiabá, Guiratinga, Comunidade Pantanalzinho, Vajeria e Assentamento Baia do Campo. 
Tabela 1 - Dados sobre local de nascimento e o tempo de moradia no local. Comunidade São Benedito, Poconé, 2014.

\begin{tabular}{cccc}
\hline Local de Nascimento & Mais de $\mathbf{4 0}$ anos no local & Menos de 39 anos no local & Total \\
\hline São Benedito & $22(53,65 \%)$ & $10(24,39 \%)$ & 32 \\
Outros locais & $7(17,07 \%)$ & $2(4,87 \%)$ & 9 \\
\hline Total & 29 & 12 & 41 \\
\hline
\end{tabular}

* Valores entre parênteses representam a porcentagem em relação ao total de entrevistados.

No que se refere à religiosidade, $100 \%$ dos entrevistados são católicos. Isso é demonstrado pelos moradores nas manifestações culturais da comunidade, ex: na semana que antecede à festa de São Benedito é realizada novena em todas as casas da comunidade, e cada casa recebe a imagem de São Benedito.

\section{RECURSOS VEGETAIS UTILIZADOS PELA POPULAÇÃO LOCAL}

\subsection{As unidades de paisagens}

\subsubsection{Os quintais e as roças}

Os quilombolas dessa comunidade vivem do cultivo de mandioca nas roças, quintais com frutas e da criação de pequenos animais domésticos. Nesse sistema agroambiental, predomina a cultura da mandioca, sendo cultivada em $100 \%$ dos espaços visitados. É utilizada sobretudo na fabricação de farinha de mandioca, principal fonte de renda para subsistência das famílias.

A produção agrícola é para o consumo da casa e sustento da família, a produção de farinha é realizada na Associação Rural da Comunidade local. O transporte para comercialização nas cidades próximas é feito de carro particular, ou, quando a família tem produção suficiente para vender, eles alugam um caminhão para o transporte. Foi observado na área que os roçados de mandioca têm papel importante para os quilombolas da comunidade São Benedito, pois são os principais produtos alimentares tanto para a subsistência quanto para a comercialização na forma de farinha de mandioca. A produção atual de farinha de mandioca é de $600 \mathrm{~kg} /$ mês vendido a fardos de $20 \mathrm{~kg}$ em média a $\mathrm{R} \$ 90,00$, valor de venda estabelecido para todas as famílias.

Os roçados na região são conhecidos como áreas para cultivo de mandioca, milho e banana. Apresentam uma área média de
2,5 ha e são feitos a partir do corte e queima da vegetação, sendo utilizada a enxada no preparo do solo. Os produtores não têm uma época como padrão para o plantio, semeadura e colheita, porém começam o preparo da terra entre os meses de setembro e outubro, sendo que todos os agricultores trabalham sozinhos ou com a família, não contratam mão de obra para o trabalho. A semeadura inicia-se no mês de novembro e dezembro, época de chuva no local, e a colheita costuma ser em outubro e adiante. Porém essas datas não costumam ser uma regra na comunidade São Benedito, pois produtores estão colhendo mandioca o ano todo e sempre renovando o plantio.

Para o plantio de mandioca, as manivas são oriundas do próprio local ou trazidas de outras comunidades. Além da mandioca, observou-se a introdução de culturas como o milho e banana na mesma área e de algumas frutíferas como mamão, abacaxi, abóbora e melancia. Para Machado et al. (2008), os principais aspectos da agrobiodiversidade estão relacionados com a segurança alimentar, composição da renda, conservação de recursos genéticos e da diversidade cultural associada às populações locais e povos indígenas. Assim, a produção destina-se na sua maioria para a subsistência, e o excedente, para a venda, auxiliando na renda da família (MARTINS et al., 2012).

Segundo os moradores, a escolha da área para implantação dos roçados se dá nas proximidades das matas ripárias, paisagem predominante na comunidade (Figura 1). Ainda, os entrevistados relatam diversos problemas com pragas nas roças de mandioca, porém, em relação à qualidade do solo, a maioria deles o consideram fértil. Quando questionados sobre derrubadas e queimadas para plantio, a maioria dos entrevistados disse não fazer queimada, e quase todo o procedimento do plantio de mandioca costuma ser feito manualmente. 

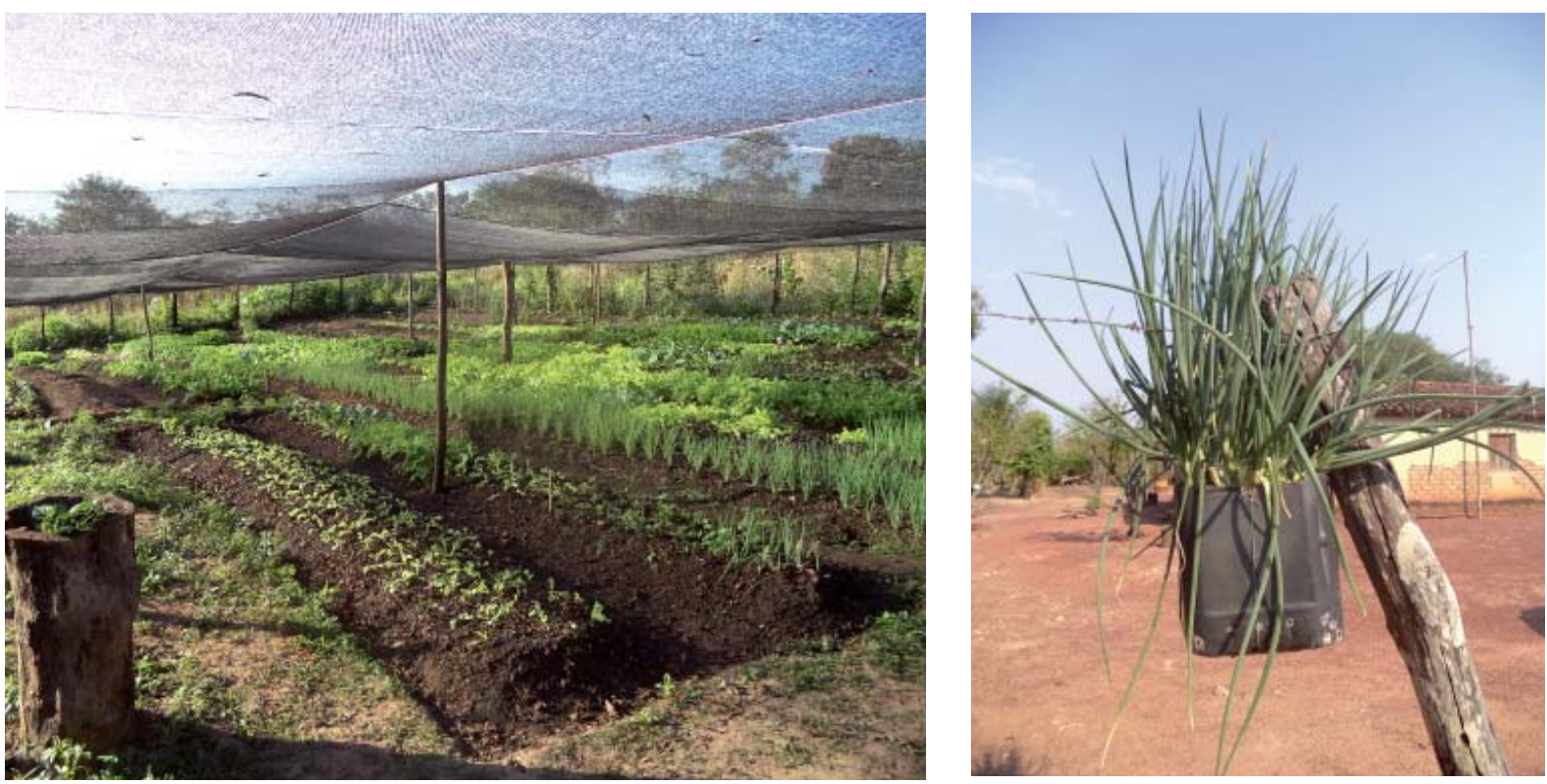

Figura 1 - Horta comunitária das famílias da comunidade São Benedito (esquerda), canteiros suspensos de hortaliças nos quintais da Comunidade (direita).

Os quintais visitados apresentaram uma área mediana de 1000 a $2000 \mathrm{~m}^{2}$, e todos se localizavam no entorno das residências. O mesmo foi verificado por Sánchez (2014) na Comunidade Água Fria, Chapada dos Guimarães. Poucos quintais possuem horta, isso ocorre porque na comunidade há uma horta comunitária para as famílias, e, dessa forma, elas se dividem nos cuidados a ela. É comum nos quintais encontrar pequenos cultivos suspensos de cebolinha, pimenta e salsinha, feitos com recipientes reutilizáveis de óleo e madeira provenientes de derrubadas para abertura de novas áreas para roça, manejando-se, de forma orgânica, sem o uso de agrotóxicos e adubos químicos (Figura 2). A produção é destinada somente para a subsistência da família, e a mão de obra é familiar, principalmente de mulheres.

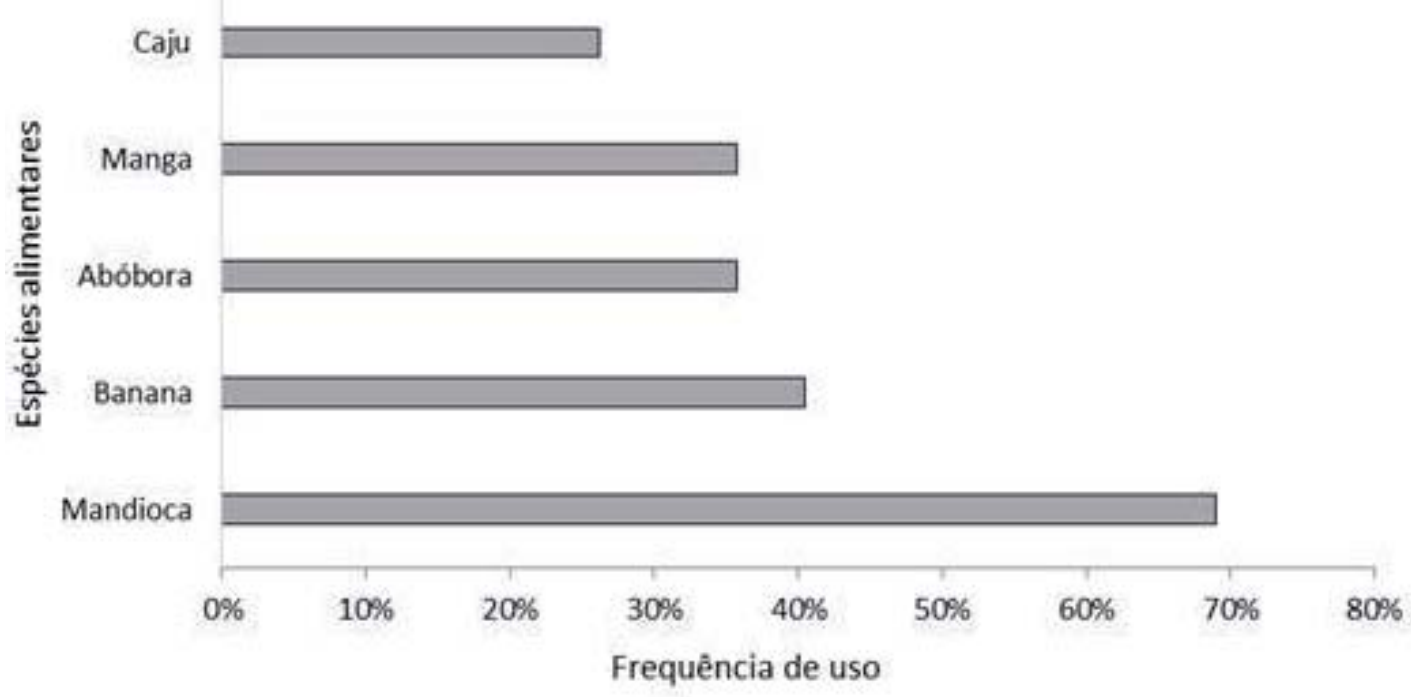

Figura 2 - Principais plantas alimentares encontradas nos quintais e roças quilombolas na comunidade São Benedito, Poconé, Mato Grosso. 2014. 
Em torno dos quintais, predomina o cultivo de um pequeno pomar que atende à demanda familiar. A maioria das frutíferas encontradas é nativa da região e preservada servindo de complemento para a alimentação. Também é comum nos quintais o plantio de pequenas quantidades de mandioca para o consumo familiar, pois a curta distância até o local facilita o acesso das famílias no dia a dia. Os quintais na comunidade São Benedito apresentam características semelhantes às descritas por Noda et al. (2002), Martins et al. (2012) por apresentarem uma área relativamente grande, cujos espaços são destinados ao manejo de árvores, arbustos e ervas, para diferentes finalidades, com cultivos perenes e anuais, cultivados em consórcio com pequenos animais.

Nos quintais da comunidade local, identificou-se um total de 54 espécies vegetais (Tabela 2), sendo distribuídas em 34 famílias botânicas, destacando-se: Lamiaceae, Poaceae, Asteraceae, Cucurbitaceae, Malvaceae e Rutaceae. Das 54 espécies, 29 são medicinais utilizadas no tratamento de doenças, com expressividade para as famílias Lamiaceae, Asteraceae e Poaceae. Pasa (2004) e Sanches (2014), pesquisando a unidade de paisagem da Comunidade Água Fria em Chapada dos Guimarães e Comunidade Conceição Açu, destacam que $64,72 \%$ das espécies são para fins medicinais.
Quanto às alimentares, 27 espécies são utilizadas de diversas formas na dieta dos moradores locais, com expressividade para as famílias: Cucurbitaceae, Anacardiaceae e Rutaceae. Diferente de outros trabalhos, essas famílias não são encontradas como as mais representativas em outros estudos etnobotânicos no país, como em Pasa (2004) e Borges (2009), nos quais tais famílias tiveram baixa e nenhuma representatividade.

Dentre as plantas alimentares (Figura 3), destacam-se a mandioca, a banana e a abóbora. A Mandioca (Manihot esculenta Crantz) apresentou maior número de citações e frequência relativa de $69,05 \%$, e a banana, de $40,48 \%$, ambas com alta densidade, ou seja muitas plantas por área. Verificou-se uma preferência dos quilombolas pelo plantio de abóbora, sendo encontrada na maioria dos quintais e roças, isso ocorre porque a espécie é a mais utilizada para o plantio em consórcio nas roças de mandioca.

Pasa (2004) ressalta que a categoria de uso de uma espécie vegetal pode ser cumulativa, uma espécie pode ser utilizada para a alimentação e ser medicinal. Os dados encontrados nessa comunidade revelam que a multiplicidade de usos está representada por quatro espécies, coco Bahia, feijão - Andu, Hortelã e Abacate. 
Tabela 2 - Famílias e espécies encontradas nas roças e quintais da comunidade São Benedito, Poconé, MT, Brasil, 2014.

\begin{tabular}{|c|c|c|c|c|}
\hline Família botânica/espécie & Nome popular & FA & FR & Categoria de uso \\
\hline \multicolumn{5}{|l|}{ Acanthaceae } \\
\hline Justicia pectoralis Jacq. & Anador & 2 & 4,76 & me \\
\hline \multicolumn{5}{|l|}{ Alliaceae } \\
\hline Allium fistulosum L. & Cebolinha & 9 & 21,43 & al \\
\hline \multicolumn{5}{|l|}{ Amaranthaceae } \\
\hline Alternanthera brassiliana Kuntze. & Terramicina & 5 & 11,90 & me \\
\hline \multicolumn{5}{|l|}{ Anacardiaceae } \\
\hline Manguifera indica $\mathrm{L}$. & Manga & 15 & 35,71 & al \\
\hline Anacardium sp. Humile A. St. Hil. & Caju & 11 & 26,19 & al \\
\hline \multicolumn{5}{|l|}{ Annonaceae } \\
\hline Annona squamosa L. & Ata & 5 & 11,90 & al \\
\hline \multicolumn{5}{|l|}{ Arecaceae } \\
\hline Orbignya oleifera Burret. & Coco- Babaçu & 3 & 7,14 & al \\
\hline Cocos nucifera L. & Coco da Bahia & 3 & 7,14 & me, al \\
\hline \multicolumn{5}{|l|}{ Asteraceae } \\
\hline Camarea ericoides St. Hil. & Arnica do campo & 8 & 19,05 & me \\
\hline Matricaria recutita $\mathrm{L}$. & Camomila & 15 & 35,71 & me \\
\hline Lactuca sativa L. & Alface & 2 & 4,76 & al \\
\hline \multicolumn{5}{|l|}{ Bignoniaceae } \\
\hline Jacaranda semiserrata $C$. & Carobinha & 2 & 4,76 & me \\
\hline \multicolumn{5}{|l|}{ Brassicaceae } \\
\hline Brassica oleracea D.C. & Couve-folha & 3 & 7,14 & al \\
\hline \multicolumn{5}{|l|}{ Caricaceae } \\
\hline Carica papaya L. & Mamão & 7 & 16,67 & al \\
\hline \multicolumn{5}{|l|}{ Chenopodiaceae } \\
\hline Coronopus didymus (L.) Smith. & Erva de Santa Maria & 7 & 16,67 & me \\
\hline \multicolumn{5}{|l|}{ Cochlospermaceae } \\
\hline Clocospermum regium & $\begin{array}{l}\text { Algodãozinho do } \\
\text { cerrado }\end{array}$ & 2 & 4,76 & me \\
\hline \multicolumn{5}{|l|}{ Convolvuláceas } \\
\hline Ipomea batatas & Batata doce & 4 & 9,52 & al \\
\hline \multicolumn{5}{|l|}{ Cucurbitaceae } \\
\hline Cucurbita moschata Dusch. & Abóbora & 15 & 35,71 & al \\
\hline Citrullus lanatus (Thunb.) Mansf. & Melancia & 10 & 23,81 & al \\
\hline Cucumis anguria $\mathrm{L}$. & Maxixe & 4 & 9,52 & al \\
\hline \multicolumn{5}{|l|}{ Dioscoreaceae } \\
\hline Dioscorea trifida L. f. & Cará & 2 & 4,76 & al \\
\hline \multicolumn{5}{|l|}{ Euphorbiacea } \\
\hline Manihot esculenta Crantz. & Mandioca & 29 & 69,05 & al, ou \\
\hline Ricinus communis L. & Mamoma roxa & 3 & 7,14 & me \\
\hline \multicolumn{5}{|l|}{ Fabaceae } \\
\hline Cajanus cajan (L) Hunth. & Feijão andú & 4 & 9,52 & me, al \\
\hline Stryphnodendron adstringens (Mart.) Coville & Barbatimão & 3 & 7,14 & me \\
\hline \multicolumn{5}{|l|}{ Lamiaceae } \\
\hline Plectranthus barbatus Andrews. & Boldo & 9 & 21,43 & me \\
\hline Lippia Alba (Mill) N. E. Br & Erva cidreira & 8 & 19,05 & me \\
\hline
\end{tabular}




\begin{tabular}{|c|c|c|c|c|}
\hline Família botânica/espécie & Nome popular & FA & FR & Categoria de uso \\
\hline Mentha sp. & Hortelã & 3 & 7,14 & al, me \\
\hline Rosmarinus officinalis L. & Alecrim & 2 & 4,76 & me \\
\hline \multicolumn{5}{|l|}{ Lauraceae } \\
\hline Persea americana Mill. & Abacate & 6 & 14,29 & al, me \\
\hline Persea americana Mill. & Abacate & 4 & 9,52 & al \\
\hline \multicolumn{5}{|l|}{ Loganiaceae } \\
\hline Strychnos pseudoquina A. St.-Hil. & Quina & 6 & 14,29 & me \\
\hline \multicolumn{5}{|l|}{ Lythraceae } \\
\hline Lafoensia pacari St. Hil. & Mangava brava & 4 & 9,52 & me \\
\hline \multicolumn{5}{|l|}{ Malpighiaceae } \\
\hline Malpighia glabra L. & Acerola & 6 & 14,29 & al \\
\hline \multicolumn{5}{|l|}{ Malvaceae } \\
\hline Gossypium herbaceum L. & Algodão branco & 6 & 14,29 & me \\
\hline Abelmoschus esculentus (L.) Moench. & Quiabo & 4 & 9,52 & al \\
\hline Waltheria douradinha A. St.-Hil. & Douradinha & 3 & 7,14 & me \\
\hline \multicolumn{5}{|l|}{ Moraceae } \\
\hline Morus nigra L. & Amora & 3 & 7,14 & al \\
\hline \multicolumn{5}{|l|}{ Musaceae } \\
\hline Musa paradisiaca $L$. & Banana & 17 & 40,48 & al \\
\hline \multicolumn{5}{|l|}{ Myrtaceae } \\
\hline Psidium guajava L. & Goiaba & 5 & 11,90 & al \\
\hline \multicolumn{5}{|l|}{ Plantaginaceae } \\
\hline Scoparia dulcis L. & Vassourinha & 7 & 16,67 & me \\
\hline \multicolumn{5}{|l|}{ Poaceae } \\
\hline Zea mays L. & Milho & 11 & 26,19 & al \\
\hline Cymbopogon citratus (D.C) Stapf & Capim cidreira & 7 & 16,67 & me \\
\hline Saccharum officinarum L. & Cana-de-açúcar & 6 & 14,29 & me \\
\hline Holcus Mollis L. & Erva molar & 3 & 7,14 & me \\
\hline \multicolumn{5}{|l|}{ Rhamnaceae } \\
\hline Rhamnidium elaeocarpum Reiss. & Cabriteiro & 3 & 7,14 & me \\
\hline \multicolumn{5}{|l|}{ Rutaceae } \\
\hline Citrus sinensis L. Osbeck. & Laranja & 4 & 9,52 & al \\
\hline Citrus limonium Osb. & Limão & 9 & 21,43 & al \\
\hline Ruta graveolens $\mathrm{L}$. & Arruda & 5 & 11,90 & me \\
\hline \multicolumn{5}{|l|}{ Solanaceae } \\
\hline Capsicum L. & Pimenta & 4 & 9,52 & al \\
\hline \multicolumn{5}{|l|}{ Verbenaceae } \\
\hline Stachytarpheta Vahl. & Gervão & 6 & 14,29 & me \\
\hline \multicolumn{5}{|l|}{ Xanthorrhoeaceae } \\
\hline Aloe vera (L.) Burman $\mathrm{f}$. & Babosa & 3 & 7,14 & me \\
\hline \multicolumn{5}{|l|}{ Zingiberaceae } \\
\hline Costus spicatus (Jacq.) Sw & Cana do Brejo & 3 & 7,14 & me \\
\hline
\end{tabular}

Legenda: A=Alimentar; Me=Medicinal; FA: Frequência absoluta; FR: Frequência relativa 
Na categoria medicinal (Figura 3), destacaram-se a Camomila $(35,71 \%)$, o Boldo
$(21,43 \%)$, Erva Cidreira (19,05\%), seguidos do Capim Cidreira (16,67\%), e Quina (14,29\%).

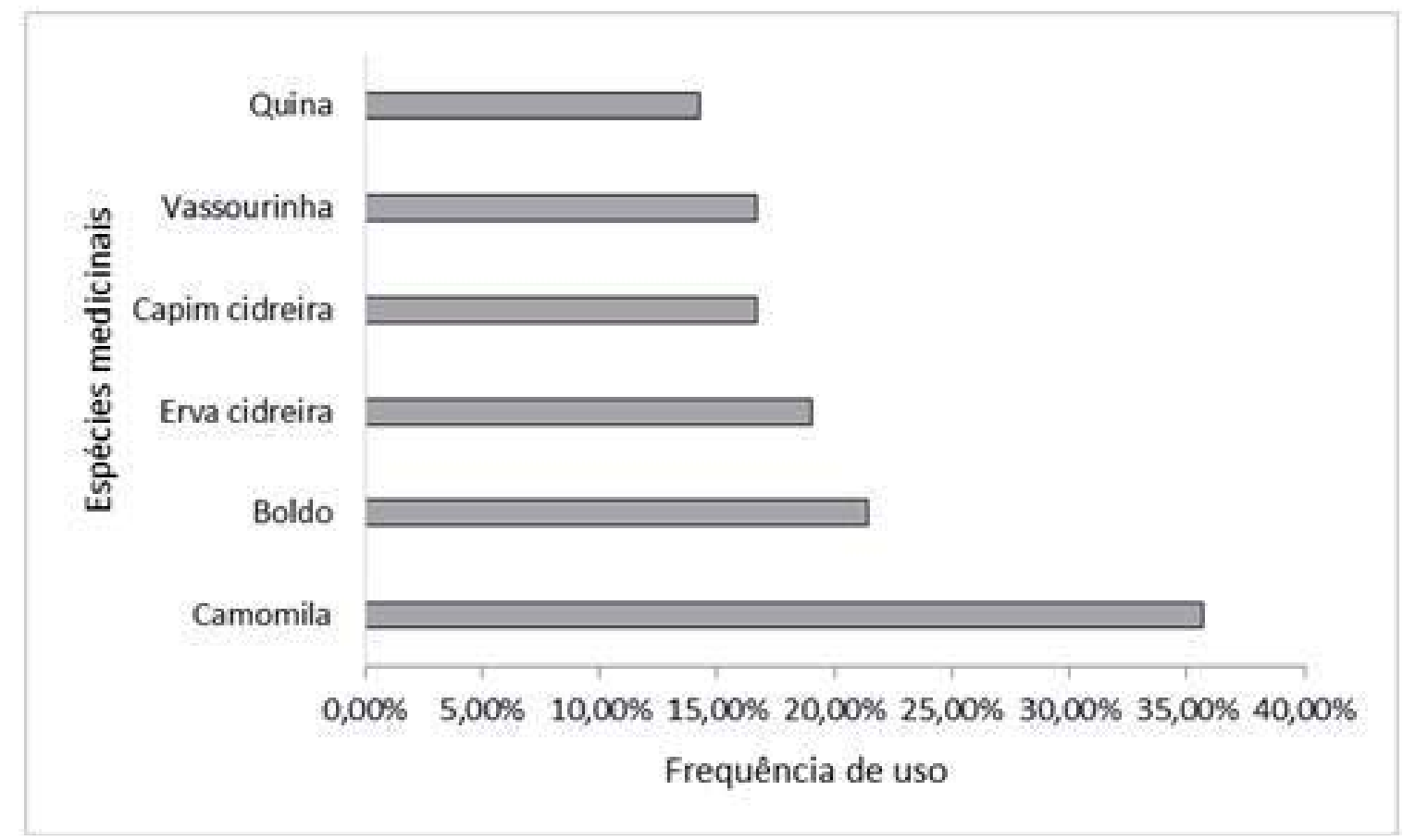

Figura 3 - Principais plantas medicinais encontradas nos quintais quilombolas na comunidade São Benedito, Poconé, Mato Grosso, 2014.

Um dos fatores que influencia o conhecimento e uso de plantas medicinais é a disponibilidade de espécies serem utilizadas e a distância em relação ao centro urbano, isso faz com que as espécies medicinais sejam a primeira opção para a cura das enfermidades dos moradores da comunidade São Benedito. As plantas medicinais encontram-se nos quintais, e a maioria delas é preparada em formar de decocção ou "machucadas", conforme o dizer local no relato abaixo:

[...] depende muito das plantas sabe, mas as foia nois costuma machuca elas e abafa com água quente, e as casca nois tira com cuidado pra não machuca a árve ai é só ferve, amorna e toma, não tem remédio meio pra nois do que esse do quintal (Sra. I.A.G, 71 anos).

Os entrevistados disseram que as plantas medicinais são importantes, atribuindo essa importância ao fato de serem recursos naturais benéficos à saúde. A maioria dos entrevistados acredita que o uso de plantas medicinais não faz mal a saúde, porém tem consciência do uso correto das plantas, ou seja, se baseiam nos ensinamentos das outras gerações.

O fato de a maioria dos entrevistados ter preferência em utilizar plantas medicinais para a manutenção ou recuperação da saúde é, de certa forma, um aspecto positivo, pois, além de fortalecer práticas tradicionais quanto ao uso e conhecimento tradicional de plantas medicinais, é uma atividade que propicia o contato direto com a flora local. Por outro lado, a noção de que as plantas medicinais não fazem mal à saúde é uma questão interessante a ser levantada na própria comunidade.

\section{CONSIDERAÇÕES FINAIS}

A partir dos resultados, foi possível concluir que os quilombolas da comunidade São Benedito utilizam sistemas de produções tradicionais com características semelhantes às demais comunidades tradicionais da Baixada Cuiabana, mesmo sofrendo a influência da proximidade dos centros urbanos. As roças e quintais apresentam uma diversidade de 
espécies vegetais úteis, as quais são utilizadas e manejadas pelos agricultores para garantir a oferta de produtos alimentícios e medicinais para subsistência e geração de renda das famílias. Esses espaços demonstram a importância do manejo e da conservação da agrobiodiversidade em locais e manutenção das tradições culturais de plantio em quintais e roças na comunidade local.

\section{REFERÊNCIAS}

ALBUQUERQUE, U. P. Introdução à etnobotânica. 2. ed. Rio de Janeiro: Interciência, 2005. 93 p.

BORGES, R.; PEIXOTO, A. L. Conhecimento e uso de plantas em uma comunidade caiçara do litoral sul do Estado do Rio de Janeiro, Brasil. Acta Botanica Brasilica, v. 23, n. 3, p. 769-779, 2009.

CABALLERO, J. La Etnobotânica. In: BARRERA, A. (Ed.). La Etnobotânica: três puntos de vista y uma perspectiva. Xalapa: INIREB, 1979. p. 27-30.

CARNEIRO, M. R. B. A flora medicinal no centro oeste do Brasil: um estudo de caso com abordagem etnobotânica em Campo Limpo de Goiás. 2009. 243 f. Dissertação (Mestrado em Sociedade, Tecnologia e Meio Ambiente) - Universidade Evangélica de Goiás, Anápolis, GO.

CONWAY, G. The properties of agroecosystems. Agricultural Systems, Essex, v. 24, n. 2, p. 95-117, 1987.

DELWING, A. B.; FRANKE, L. B; BARROS, I. B. I. de; PEREIRA, F. S.; BARROSO, C. M. A etnobotânica como ferramenta da validação do conhecimento tradicional: manutenção e resgate dos recursos genéticos. In: CONGRESSO BRASILEIRO DE AGROECOLOGIA, 2., 2007. Resumos... ABA Agroecologia, 2007. p. 421-425.

DIEGUES, A. C. O mito moderno da natureza intocada. 3. ed. São Paulo: HUCITEC, 2001. 102 p.

FOOD AND AGRICULTURE ORGANIZATION OF THE UNITED NATIONS (FAO). Sustaining agricultural diversity in agro-ecosystems functions. Roma: FAO, 1999. $43 \mathrm{p}$.

INSTITUTO BRASILEIRO DE GEOGRAFIA E ESTATÍSTICA (IBGE). Censo Demográfico 2010. 2010. Disponível em: <http://www.cidades.ibge.gov.br/ xtras $/$ perfil.php?lang $=\&$ codmun $=510300>$. Acesso em: 4 mar. 2015.

MACHADO, A. T.; SANTILLI, J.; MAGALHÃES, R. A. Agrobiodiversidade com enfoque agroecológico: implicações conceituais e jurídicas. Brasília: Embrapa Informação Tecnológica; Embrapa- Secretaria de Gestão e Estratégia, 2008. 98 p.

MARTINS, O. M. W.; MARTINS, O. M. L.; PAIVA, S. F.; MARTINS, O. J. W.; JUNIOR, L. F.S. Agrobiodiversidade nos quintais e roçados ribeirinhos na comunidade Boca de Môa - Acre. Biotemas, Florianópolis, SC, v. 25, n. 3, p. 111-120, 2012.

MARZALL, K. Fatores geradores da agrobiodiversidade - Influências socioculturais. Revista Brasileira de Agroecologia, Porto Alegre, RS, v. 2, n. 1, p. 237-240, 2007.

MEIHY, J. C. S. B. Manual de história oral. São Paulo: Loyola, 1996. 78 p.

NODA, S.; NODA, H.; MARTINS, A. L. U. Papel do processo produtivo tradicional na conservação dos recursos genéticos vegetais. In: RIVAS A.; FREITAS, C. E. C. (Org.). Amazônia uma perspectiva interdisciplinar. Manaus: Editora da Universidade do Amazonas, 2002. p. 155-178.

PASA, M. C. Etnobiologia de uma comunidade riberinha no Alto da Bacia do Rio Aricá Açu, Cuiabá, Mato Grosso, Brasil. 2004. 238 f. Tese (Doutorado em Ecologia e Recursos Naturais) - Universidade Federal de São Carlos, São Carlos, SP.

PASA, M. C. Abordagem etnobotânica na comunidade de Conceição-Açú, Mato Grosso, Brasil. Polibotánica, Ciudad de México, v. 31, p. 169-197, 2011.

PRANCE, G. T. Etnobotânica de algumas tribos amazônicas. 2. ed. Petrópolis, RJ: SUMA Etnológica Brasileira - Etnobiologia, 1987. p. 119-134.

SÁNCHEZ, D. C. M. A etnobotânica e as unidades de paisagem na comunidade Água Fria, Chapada dos Guimarães, MT, Brasil. 2014. 123 f. Dissertação (Mestrado em Ciências Florestais e Ambientais) - Universidade Federal de Mato Grosso, Cuiabá, MT.

SANTOS, J. C. Análise da rentabilidade, sob condições de risco, de um sistema agroflorestal adotado por pequenos produtores de cacau na região da Transamazônica, Pará. 1996. 128 f. Dissertação (Mestrado em Economia Rural) - Universidade Federal do Ceará, Fortaleza. 